\section{De aculturados a índios com cultura: estratégias de representação do movimento de professores tapebas em zonas de contato*} From acculturated to Indians with
culture: representation strategies of
the Tapeba teachers' movement in contact zones

\author{
Max Maranhão Piorsky Aires**
}

Resumo: Este artigo analisa duas situações: a estratégia de "resgate" da história e cultura da Igreja Católica que acreditou poder salvar os tapebas do suposto processo de aculturação, por volta de meados da década de 1980. Num segundo momento, é feita uma análise do período posterior e recente que diz respeito à emergência do professor indígena como figurachave da mobilização étnica. A intenção é explorar os discursos e práticas empregados para representar as populações indígenas no Ceará e, também, o modo como estas representações são apropriadas pelos professores tapebas, de Caucaia, Ceará, no Nordeste brasileiro.

Palavras-chaves: Professores Indígenas; Educação Escolar Indígena; Antropologia da Educação.

Abstract: This article analyses two situations: the strategy of "redeeming" the history and culture of the Catholic Church which believed in their power to save the Tapebas from the supposed process of acculturation, in the middle of the $80 \mathrm{~s}$, and, secondly, I analyse a recent period, after the other, which addresses the emergence of the indigenous teacher as the key figure in ethnic mobilization. The intention is to study the discourses and practices used to represent the indigenous populations in Ceará and, also, the way in which these representations are appropriated by the Tapeba teachers in Caucaia, Ceará, in the Brazilian northeast.

Key words: Indigenous teachers; Indigenous Schooling; Anthropology and Education.

\footnotetext{
* Agradeço o apoio, comentários, críticas e sugestões de Isadora Araújo, Iana Meireles, Joceny Pinheiro, Neusa Gonçalves, Edvar Costa e aos pareceristas anônimos da Revista Tellus. Não custa nada repetir que o conteúdo do artigo é de minha inteira responsabilidade.
}

\footnotetext{
** Professor Adjunto de Antropologia, na Universidade Estadual do Ceará (UECE) vinculado ao curso de Ciências Sociais e ao Programa de Pós-Graduação em Políticas Públicas e Sociedade. E-mail: maxm@uece.br.
} 


\section{Introdução}

O antropólogo Charles Hale (2002) fez uma interessante análise da relação entre dois fenômenos da década de 1990: a mobilização dos movimentos indígenas e a adoção da doutrina neoliberal pelos países latinoamericanos. Na direção contrária das investigações que colocam estes fenômenos em oposição, Hale intitulou esta relação de neoliberalismo multicultural assinalando, ao mesmo tempo, para a defesa e engajamento por parte dos proponentes da ideologia neoliberal em favor dos direitos culturais indígenas, abrindo de certo modo, espaços na estrutura de oportunidades políticas para a conquista de direitos, mas, por outro lado, avançando na imposição de suas agendas políticas e regulando os espaços de participação indígena e normatização das diferenças culturais. Não somente Hale, enfocando o caso da Guatemala, mas diversos antropólogos, pesquisando no Peru (Dean, 2002; Garcia, 2004), Bolívia (Gustafson, 2002; Antequera, 2003), Colômbia (Jackson, 1995a), Argentina (Briones, 2002), e Brasil (Souza Lima et al, 2004) assinalam que as reformas neoliberais na América Latina têm provocado efeitos contraditórios para as populações indígenas na implementação das agendas políticas de educação intercultural.

$O$ foco centra-se na investigação da conjuntura de forças que juntas produzem os espaços de participação e o disciplinamento destes mesmos espaços. Seguindo as sugestões de Escobar $(1997,2005)$, Souza Lima (1995 - FALTA), Collet (2001) e Paladino (2002), trato a educação escolar indígena como objeto de discursos e práticas e procuro seguir de perto a sugestão de Lopes da Silva (2001) na qual as possibilidades de uma antropologia da educação escolar indígena deve fazer uso dos avanços da Etnologia Indígena.

Privilegio duas escalas simultâneas como tópico de investigação etnográfica: (a) a constituição de um campo discursivo pela Igreja Católica, reforçado pela agenda do multiculturalismo neoliberal adotada pela Secretaria Estadual de Educação, e (b) seus impactos na mobilização dos professores indígenas, enfocando, especialmente, suas estratégias de mobilização, adequação e produção de saberes em face das políticas multiculturais. Direciono a análise para sobre as seguintes situações: $1^{\circ}$ ) a ação da Arquidiocese de Fortaleza e a estratégia de "resgate" da história e cultura, esse mito do indigenismo heróico, para usar uma expressão empregada por Baines (2000), que acreditou poder salvar os tapebas do suposto processo de aculturação; $2^{\circ}$ ) o período posterior e recente que diz respeito à emergência do professor indígena como uma figura-chave nas 
mobilizações étnicas, procurando entender de que modo eles apropriam-se de imagens produzidas no período anteriormente mencionado.

A minha intenção é apontar para a natureza pluralista das ações e representações criadas pelo movimento dos professores indígenas que acontecem em meio a uma complexa conjuntura. Exploro situações nas quais os professores indígenas têm produzido respostas interessantes que não podem ser captadas simplesmente por conceitos ou idéias como "invenção" ou essencialismo estratégico.

A investigação para este artigo foi realizada principalmente entre os anos de 1998 e 1999, seguidas de observações esporádicas até o presente momento. Partindo de uma estratégia de pesquisa multilocal que envolvia consulta de documentos em órgão públicos, nos arquivos da Igreja Católica e em jornais de notícias, participação em inúmeras reuniões e eventos, uma parte significativa da investigação foi realizada no município de Caucaia, onde os índios tapebas residem ${ }^{1}$.

\section{A ação da Igreja Católica: "resgatando" a cultura e memória dos Tapebas}

Por volta da primeira metade dos anos de 1980, a Arquidiocese de Fortaleza iniciou as suas ações com os tapebas e com a população regional de Caucaia, com a intenção de solucionar o problema agrário no município, de uma só vez, para índios e não-índios. As intervenções da Igreja Católica, em especial da Equipe de Apoio às Comunidades Rurais ${ }^{2}$, podem ser situadas no contexto das experiências com educação popular desenvolvidas pelo Movimento de Educação de Base (MEB) ${ }^{3}$ que possibilitou uma linguagem para o tema da cultura. No Ceará, as atividades do MEB tiveram início em 1963. Por meio de transmissões radiofônicas, o processo educacional era acompanhado por um monitor junto com os grupos de jovens e adultos. O monitor também era encarregado de fazer a mobilização da população local em torno de um ideal de "comunidade" com a realização de tarefas que permitissem a "ajuda mútua", o desenvolvimento de "trabalhos comunitários", a sindicalização, reuniões para discussão e solução dos problemas locais. Com o golpe militar de 1964, os temas foram despolitizados e a substituição da equipe nacional fizeram com que o movimento se reconstituísse em bases distintas das propostas iniciais. No período de 1966 a 1970, o MEB entra em declínio técnico-financeiro e os processos de escolarização formal destinados à suplência dos estudos e alfabetização passam a ser a tônica da política (Damasceno, 1990, p. 97-101). 
O trabalho local do MEB ganhou outros rumos com a chegada de Dom Aloísio Lorscheider a Fortaleza, em abril de 1973. Nomeado arcebispo da capital cearense pelo Papa Paulo VI, no início de agosto, tomou posse e, por volta do final dos anos de 1970, empreendeu uma série de mudanças na direção pastoral da Arquidiocese. Estas transformações foram orientadas pelos movimentos de revisão doutrinária da igreja ${ }^{4}$ que reconciliou a instituição com o mundo moderno (Montero, 1995; 2006), mas também pela própria experiência pessoal de Lorscheider.

O cardeal ${ }^{5}$, nascido numa cidade do interior do Rio Grande do Sul, ao chegar à capital cearense não conhecia o Ceará e muito pouco da região Nordeste. Segundo ele próprio, num artigo escrito para a Revista Concílio, afirmou que, antes de chegar ao Ceará e conhecer a "pobreza" e as Comunidades Eclesiais de Base (CEBs), ele era simplesmente um bispo "conservador" da diocese de Santo Ângelo-RS. A chegada ao Ceará e o convívio com o "povo pobre" teria sido uma "conversão" ao "povo". Esta conversão associada às transformações pelas quais a igreja passava, fizeram com que a Arquidiocese de Fortaleza direcionasse suas ações para uma maior participação dos leigos e uma guinada em direção a uma leitura da realidade que incorporou instrumentos analíticos das Ciências Sociais e propunha a reflexão, a partir de valores cristãos, de temas como engajamento político, participação popular, reflexão sobre as desigualdades socioeconômicas, transformação social e, sobretudo, a cultura.

Com essa linha de ação, Dom Aloísio, como era conhecido, organizou a Equipe de Assessoria às Comunidades Rurais, formada por leigos e constituída especificamente para trabalhar com a população do meio rural, a Equipe levou adiante a proposta pedagógica do MEB e o projeto "educacional-evangelizador" (Arquidiocese, 1986).

No entanto, com a "conversão" do Cardeal e com os novos rumos assumidos pela igreja, no início dos anos de 1980, foi inevitável um confronto com o MEB Nacional, pois com o declínio dos fluxos de recursos técnicos e financeiros, a busca por fundos internacionais para financiamento das ações não fora uma prática aceita. E, sobretudo, com a "opção preferencial pelos pobres" e a implementação de uma nova proposta metodológica de ação pedagógica diferente da linha traçada nacionalmente passou a incomodar o MEB nacional.

O rompimento significou uma espécie de virada metodológica rumo ao "povo pobre" na medida em que retirou do agente pastoral, do "animador" e monitor das comunidades a função educacional e passou a 
valorizar os saberes e a cultura da população local. O trabalho da equipe, portanto, transformou-se paulatinamente na direção da elaboração de um "[...] projeto de largo alcance social, por um prazo longo, com as condições que correspondessem à dinâmica e ao movimento das comunidades". (Arquidiocese, 1986, p. 1).

Foram deixadas de lado a preocupação com os processos educativos realizados na escola para uma preocupação com a educação popular e dimensões associados à cultura, à participação sindical e política com vistas à transformação da sociedade. Sob a influência de Dom Aloísio, os planos seriam pautados numa "[...] opção preferencial pelos pobres [...] numa perspectiva de transformação das estruturas injustas, com ênfase na organização das comunidades, e como estratégia a descoberta, pelos próprios pobres, de seu valor e dos meios de luta por uma sociedade justa." (Ibid., p. 9) 6 .

O trabalho da equipe alcançou projeção no interior da Igreja; no início dos anos de 1980, eram atendidas 80 localidades em cerca de 10 municípios cearenses e três programas pautavam a ação da Equipe: educação "cooperativa popular", educação sindical e educação política. $O$ emprego da noção de cultura popular é emblemático na importância que o termo aparece para a igreja e equipe, tal concepção fazia referência à "cultura do povo", concebida como modo de vida e de organização do trabalho que permitiam impulsionar e gerar laços para o desenvolvimento espiritual e "comunitário" e também como um instrumento para a luta política, ferramenta que geraria "mais alegria", "mais coragem para lutar". A concepção de "cultura popular", seguia na mesma direção do Concílio Vaticano II, na qual tal noção passava por uma reformulação, distanciando-se de significados próximos à erudição ou educação e aproximando-se dos referenciais teóricos da Antropologia na qual cultura é tratada com "[...] dimensão do homem; todo homem, por mais ignorante que pareça, por mais atrasado, é portador de uma cultura que é preciso conhecer e compreender." (Montero, 1995, p. 232).

A "nova metodologia" adotada pela equipe consistia na identificação dentro das localidades de "[...] formas simples de cooperativismo popular" (Arquidiocese, 1986, p. 3) (roças, compras conjunta de implementos agrícolas, entre outras). Era necessário, portanto, conhecer a localidade, seus indivíduos e valores. Em seguida fazia-se uma "análise crítica" destas experiências, fundamentando-se numa leitura bíblica e em modelos que incentivaram a participação comunitária, desenvolvimento econômico e participação popular nos sindicatos na elaboração e execução dos projetos. O pressuposto que orientava as ações era a crença de 
que estes valores "comunitários" existentes gerariam as formas de engajamentos mais consistentes, superior às "formas simples", estes engajamentos seriam por meio da participação em sindicatos ou pela criação de entidades representativas (associações, conselhos comunitários e outros).

Um outro ponto importante da "nova metodologia" consistia na "vivência na comunidade", que se traduzia em práticas que enfatizavam o convívio e participação dos leigos nas atividades diárias com a população-alvo da intervenção pastoral. Este convívio permitiria ao agente pastoral um melhor conhecimento dos "valores do povo". Esta convivência era acompanhada da realização de pesquisas sobre a história da localidade, recorrendo aos primeiros moradores, e pesquisa dos ditados populares. Tais atividades eram complementadas com a realização de desfiles com produtos da região, composição e apresentação de músicas, poesias e ditados populares, concurso de cantadores, danças folclóricas, dramatizações, comidas, bebidas típicas e medicina popular. A identificação destes elementos da "cultura popular" permitiriam aos membros da Equipe não somente "valorizar" a "cultura", mas instrumentalizá-la na medida em que estas práticas eram usadas para orientar as ações pedagógicas e de mobilização política.

Apoiado nestas concepções e práticas, um dos membros da equi$\mathrm{pe}^{7}$ tomou conhecimento da existência de índios tapebas em Caucaia e, por volta de 1984, iniciou os trabalhos com "os remanescentes indígenas e miseráveis". A equipe exerceu papel decisivo na etnogênese tapeba e permitiu o reconhecimento público de que no Ceará havia índios ${ }^{8}$, desencadeando um processo de organização comunitária e política desta população, e abrindo possibilidades de conquista dos direitos indígenas, inicialmente em torno da terra. O papel decisivo que a igreja desempenhou no reconhecimento foi alcançado por meio da estratégia de estabelecimento de agendas políticas comuns, para índios e população rural, no tocante à regularização fundiária. Portanto, a resolução do conflito da terra e de outros problemas sociais de índios e não-índios pautou as ações de entrada da equipe em Caucaia.

O reconhecimento público dos tapebas, a importância e experiência acumulada pela equipe possibilitou uma conjuntura favorável à canalização de recursos financeiros para os índios, que se traduzia principalmente em tornar disponíveis benefícios materiais para as populações, tais como a distribuição de cestas básicas, a ajuda na construção de casas em algumas localidades, consultas médicas e ajudas financeiras para a compra de remédios e tratamentos de doenças, e outras doações. Um benefício que ficou conhecido no local, e que ainda hoje é lembrado, foi a 
distribuição do leite, que ficou conhecida como a "reunião do leite" momento de encontro para distribuição deste alimento, e marco na organização dos indígenas. As práticas da equipe junto às populações rurais que incentivavam a criação de entidades associativas foi uma outra tática empregada para gerar vínculos entre as lutas políticas de índios e trabalhadores rurais de Caucaia, em 1985, por meio da fundação da Associação das Comunidades do Rio Ceará. Durante o final da década de 1980, a associação elaborou e executou uma série de projetos "socioeconômicos", muitos deles financiados por órgãos estaduais de governo e por entidades internacionais. Os projetos previam a construção de hortas e roças comunitárias, criações domésticas de peixes e aves, aquisição de redes de pesca e outros para a construção de cacimbões e chafarizes. Além da alternativa de renda, os projetos destinavam-se a favorecer os vínculos entre índios e não-índios, como atesta a justificativa do projeto citado adiante:

A implantação dessas pequenas hortas seria de grande valia para ajudar no orçamento doméstico das famílias envolvidas bem como melhorar a dieta alimentar dessas pessoas no que se refere à oferta de vitaminas (através do consumo de verduras). Seria também uma oportunidade de algumas famílias terem uma atividade coletiva de produção, possibilitando dessa maneira o enfrentamento comum dos seus problemas e dando mais força e união na luta pela reconquista de seus direitos mínimos (direitos de terra, como um bem sagrado). (Associação, 1989, s/p).

No início da década de 1990, com a mudança dos integrantes da própria Equipe de Apoio às Comunidades Rurais ${ }^{9}$, e, também, com a criação da Pastoral Indigenista, a ação passou por algumas mudanças no tocante à natureza da intervenção empreendida. Se o assistencialismo marcou até então o atendimento de demandas sociais postuladas pelos tapebas, a Pastoral Indigenista, por outro lado, passa a perceber as práticas assistenciais como um problema para a criação de vínculos políticos entre os índios e, até mesmo, entre estes e a população regional, fazendo menção aos problemas encontrados na execução do trabalho, destacando o seguinte problema: "Dependência econômica e financeira dos índios e vícios criados pela equipe anterior (Comunidades de Caucaia)" (Relatório, 1990).

Mediante esta constatação, a pastoral procurou romper com os "vícios" por meio de uma ação em prol do desenvolvimento de projetos sociais que criassem opções de renda familiar para a população indígena e não-indígena, mas que favorecessem ainda a criação de vínculos políticos na conquista da terra. Mesmo levando em conta as diferentes 
formações do corpo técnico do órgão da Arquidiocese, a postura política estava apoiada na crença de que os benefícios trazidos pelas doações, ou a implantação de projetos que beneficiassem a população indígena e nãoindígena, seriam responsáveis pela organização e a conseqüente mobilização política destes indivíduos. No documento a seguir, elaborado pela Pastoral Indigenista, a associação entre os "grupos" que executavam os projetos e a "união" em favor da "luta" pela terra são inseparáveis:

Em primeiro lugar, esses grupos deveriam funcionar para dar às pessoas alguma possibilidade de melhorar sua condição de vida, ao mesmo tempo em que as pessoas estariam juntas, tentando melhorar a sua condição de vida, teriam mais condições de lutar pela terra (terra para os índios Tapeba e terra para os não índios), como um direito sagrado. Melhorando as condições de vida e lutando pela terra, as pessoas viveriam uma experiência nova, significava que cada pessoa sairia do seu isolamento, do seu sofrimento individual, as pessoas experimentariam novas maneiras de ser e de viver. Essas novas maneiras de ser e de viver queriam dizer que as pessoas passariam a unir as suas vontades, e unir seus planos de vida. [...] Dessa forma, deixariam de usar o "Eu" para usar o "Nós". (Arquidiocese, s/d, s/p.).

No empreendimento arquidiocesano, uma outra estratégia merece destaque: a intervenção de ordem cultural que procurou revitalizar a memória e cultura indígenas (Barreto Filho, 1994; Aires, 2003). Na prática eram feitas incursões de pesquisas, de pequeno ou maior porte, em que os resultados materializavam-se na produção de múltiplos gêneros discursivos, tais como fotografias, vídeos, cartazes, folders, cartas públicas, livretos, livros, mapas, documentos internos com circulação restrita, pesquisa documental e bibliográfica que tinham a intenção de constituir conhecimento sobre os tapebas. A maioria desse material foi elaborado entre os anos de 1985 e início da década de 1990, período do indigenismo ${ }^{10}$ - momento que corresponde à constituição do campo de ação indigenista no Ceará (Barreto Filho, 1994; Valle, 2000).

As pesquisas aconteciam no contexto de disputa pela terra que requeria nas fases iniciais do processo de identificação e demarcação, "[...] a apresentação de evidências históricas sobre a antiguidade do território [e que sobre ele] os índios exerçam de modo estável e regular uma 'ocupação tradicional', isto é, que utilizem tal território segundo 'seus usos e costumes'." (Pacheco de Oliveira, 2000, p. 20-22). Se for levada em conta a especificidade da situação histórica das populações indígenas no Nordeste brasileiro, marcada pelo ressurgimento das identidades indígenas, "[...] não há como falar em território indígena no sentido atual em que empregamos o termo e que os próprios índios contemporâneos reivindicam." (Ibid., p. 21). 
No entanto, no campo da disputa simbólica, estes saberes foram concebidos como indispensáveis, pois entre outras coisas, procuravam responder às questões postas pelas exigências legais e pelos argumentos da elite local de que os tapebas não são índios, por essa razão a maioria dos gêneros discursivos versava sobre assuntos relacionados "[...] a história do Ceará e da ocupação autóctone e colonial da área onde hoje se situa o município de Caucaia [pretendendo] atestar a continuidade histórica dos tapebas com as populações pré-colombianas e a imemorialidade da ocupação" (Barreto Filho, 1992 ${ }^{11}$, 1994, p. 20), do território a partir da produção de consensos sobre os tapebas.

Uma das principais estratégias discursivas da Arquidiocese era afirmar perante o público que o "povo tapeba existe"12. Irei chamar esta tática de orientalismo ${ }^{13}$ (Said, 1996), pois esta implicava na criação de um índio fabricado, hiper-real, como diria Ramos (1995), um índio mais real que o índio real, na medida em que foram moldadas uma "cultura", uma "história" indígena e uma geografia imaginativa (Said, op.cit.) para que os tapebas correspondessem às representações da população nãoindígena. Esta relação entre índios e os agenciamentos das mais diversas organizações não é simplesmente um exercício de imaginação, mas " [...] é uma relação de poder, de dominação, de graus variados de uma complexa hegemonia [...] que apresentou um 'consenso', um 'conhecimento verdadeiro' sobre os tapebas." (Said, 1990, p. 17). Esta relação de dominação que pretendia "resgatar" e afirmar a existência da população tapeba possuía um cunho educativo, ou uma pedagogia que apresentou uma indianidade idealizada em que "[...] o índio deve continuar correspondendo à imagem daquilo que se quer preservar [...] mesmo ao preço de relações autoritárias e, sempre, reducionistas." (Gallois, 1992, p. 127).

Um dos primeiros atos para a deflagração do processo jurídicoadministrativo de regularização fundiária da Terra Indígena Tapeba foi o envio de uma carta, em 1985, ao presidente do Brasil, ao presidente da FUNAI e ao Ministério da Reforma e Desenvolvimento Agrário, solicitando "terra pra nós morar e plantar", "um posto médico, escola para os índios" (O POVO, 1985). A carta apresentou os tapebas como "índios", como um "povo", uma "nação", portanto, sujeito de direitos e abrindo a possibilidade da deflagração do processo jurídico-administrativo de reconhecimento da terra indígena ${ }^{14}$, o que de fato aconteceu. Apresentou também os tapebas como um povo sofrido ("os tapebas sofrido", "Aí vivemo lutando e sofrendo pela vida", "passa fome" etc.) e assinalou duas causas para o sofrimento: (a) as dificuldades de ordem socioeconômica ocasionada pela negação do direito à terra, saúde e edu- 
cação e, também, (b) aquilo que chamarei de transformações culturais experimentadas pelos tapebas - assunto sobre o qual falarei adiante.

Na carta há referência à morte de Perna-de-Pau, tido como um ancestral importante, e depreende-se que a morte do líder indígena foi o tema para o qual convergiram as duas causas de sofrimento a que o texto alude. A morte de Perna-de-Pau foi o motivo pelo qual os tapebas ficaram "sem terra" ("Depois que ele morreu fiquemo sem terra"), pois ela "foi invadida" e os índios "despejado[s] pelos branco[s]". A morte do "chefe" político, do "último cacique", ocasionou de uma maneira geral não somente a perda do território, mas a perda de direitos ("sem terra", "sem saúde, sem escola") e de uma situação liminar vivida pelo grupo indígena ("Depois que ele morreu fiquemo sem terra. Foi invadida. Então nós fumo andar pelo mato. Fumo despejado pelos branco", "fomo pra mata virgem com todas as criança", "perambulando sem comida"), em outras palavras, sugerindo um certo estado de desorganização social e cultural.

Os temas da morte de Perna-de-Pau, da desorganização social ou aculturação e dos modos de subsistência, bem como outros, vão se consolidado nos documentos produzidos posteriormente, como foi o caso dos textos Conversas com os Tapeba e $2^{a}$ Conversas com os Tapeba, elaborados antes mesmo dos estudos antropológico e fundiário que inauguram o processo de regularização da terra indígena, ainda no mesmo ano de 1985. No texto, montado com transcrições de trechos de entrevistas, foram vinculados a determinados espaços geográficos (matas e rios) e a uma dimensão clássica da definição antropológica de cultura, os modos de subsistência ("Caça dos Tapebas", "A Pesca no Rio Ceará" e "Andar no Mato"), e a detenção de um saber etnobotânico ("A Medicina Tapeba"), todos tidos como atividades, saberes e estilos de vida próprios dos tapebas.

Noutro esforço educativo da Arquidiocese, apareceram cartazes elaborados com a finalidade didática de auxiliar nas apresentações públicas dos tapebas em que o material era empregado para explicar a "verdadeira história" nas exposições orais que aconteciam nas reuniões da Associação das Comunidades do Rio Ceará, ou mesmo em eventos na capital cearense. Os cartazes faziam referência para o emprego do tempo verbal, no passado ("A gente tinha um jeito próprio") e, ao mesmo tempo, sugerem que os tapebas mantiveram certos aspectos de sua organização social:

Sofrimento. A nossa salvação foi continuar diferente dos brancos poderosos, forasteiros de Caucaia. A gente tinha um jeito próprio de andar - falar - pescar - caçar - casar - construir casa - amar - se divertir - comer - dormir - andar. Por causa do sofrimento, os mais velhos 
tinham medo de contar para nós o que havia acontecido. Humilhavam a gente por isso. Mas não sabe que até valeu essa humilhação!... Assim a gente não se misturou totalmente com os que não era índios". (Barreto Filho, 1992).

O "sofrimento" e a "mistura" foram também temas recorrentes nos documentos. O primeiro causado pela situação de opressão vivida ("humilhação" ou a menção à "invasão das terras", mencionados em outros cartazes) e o segundo tema, a "mistura", apontava para um saber que foi se cristalizando a respeito dos tapebas: a de que os índios não conseguiram manter de maneira eficiente mecanismos de transmissão cultural que assegurassem a manutenção de uma memória coletiva em virtude do "sofrimento", do "medo" que "os mais velhos tinham" ("Por causa do sofrimento, os mais velhos tinham medo de contar para nós o que havia acontecido") e da miscigenação, ocasionando, enfim, um processo de perdas culturais ("A gente tinha um jeito próprio") e, por outro lado, a afirmação de que, apesar da "mistura" e dos seus efeitos corruptivos e degenerativos, "a gente não se misturou totalmente". Num outro texto os tapebas foram concebidos como descaracterizados culturalmente e com uma "[...] perda de memória tribal sofrida pelos remanescentes." (Gomes, 1986 apud Barreto Filho, 1992).

Outro tema encontrado nos cartazes tratava da composição étnica do aldeamento de Nossa Senhora dos Prazeres de Caucaia, que foi apresentado como formado por três ou quatro etnias ("Na aldeia juntaram índios de 3 ou 4 nações: Potiguara - Tremembé - Cariri e talvez Jucá"). Os temas das etnias que deram origem aos tapebas estavam presentes nos primeiros esforços de compreensão etno-histórica provenientes da Fundação Nacional do Índio (FUNAI) ${ }^{15}$, do Ministério da Reforma e do Desenvolvimento Agrário (MIRAD) ${ }^{16}$ e da Arquidiocese.

Apresentarei a seguir o documento elaborado pelo MIRAD (Rola, 1986), com a assessoria da Arquidiocese. Inicialmente, o texto procurou, num único parágrafo de cinco linhas, apontar aspectos históricos de Caucaia, "antiga Vila Nova de Soure", afirmando que lá existiam e existem índios, pois o local "onde vivem os Tapeba" foi "um aldeamento estabelecido pelos jesuítas", em 1759; os tapebas, de acordo com o texto, descendem destes índios aldeados. Em seguida retoma o tema da dispersão e desorganização dos tapebas, nesse caso sem apontar a causa, "após longo processo de dispersão e desorganização", os índios voltaram a "se reunificar", sendo o momento-chave o envio da carta mencionada anteriormente (Ibid., p. 1). Num tópico intitulado Aspectos da situação da vida e da cultura, os tapebas foram apresentados, ao mesmo tempo, como uma 
população culturalmente semelhante à população regional, mas também que "preservou" regras matrimoniais sem vivenciar plenamente o processo de aculturação (Ibid., p. 5-6).

Encontra-se também noutro trecho a referência à "preservação" de aspectos relacionados aos "antepassados". O documento afirma que, "[...] apesar da estreita convivência com os brancos, os Tapeba mantém uma série de valores e costumes dos seus ancestrais." (Ibid., p. 1), como por exemplo:

[...] pescam peixes com as mãos; constroem canoas sem proa, movidas com varas; fazem o que chamam de quixó espécie de armadilha para pegar animais do mato (caça); transformam a palha de carnaúba em pincéis, vassouras, espanadores, surrão, uru, chapéu, esteira e bolsa para guardar farinha, [e para "curar"], utilizam-se de ervas e poções. (Rola, op. cit., p. 6).

Um desenho que associou os tapebas à pesca no rio Ceará tornouse uma espécie de logomarca da Associação das Comunidades do Rio Ceará. As declarações públicas da elite local também contribuíam para as representações sobre os tapebas, os discursos põem em dúvida a existência de índios em Caucaia, argumentando que no Município há "proliferação de favelas", em geral compostas por indivíduos que representam

[...] o estrato Social e Racial médio do Cearense de baixa renda. Ali há brancos, caboclos, mestiços e possivelmente alguns descendentes remotos de índios, mas totalmente aculturados. [...] uma comunidade "Sui generis", pois fala e entende a língua portuguesa como qualquer um de nós, não sabe uma só palavra do idioma indígena, está perfeitamente integrada na comunidade nacional, desconhece a cultura e tradição indígena, e que se instalou no local nos últimos dez (10) anos, oriunda de todos os recantos do Ceará. (Coelho, 1988, s/p.) 17. $^{17}$.

As idéias de índios miseráveis, sem memória e aculturados podiam ser também atestadas mediante a leitura do texto de apresentação que compõe o livreto A Medicina dos Tapebas (1988). O livro contém duas apresentações: na assinada pela equipe da Arquidiocese, os tapebas foram representados como uma população "em estado de miséria latente" em que "costumes e saberes estão pouco a pouco desaparecendo", mas que "ainda alguns praticam". Na outra apresentação, escrita pelos presidentes da Associação, o presidente do "Lado dos Brancos" e do "Lado dos Tapeba", o texto vinculou a "medicina tapeba" à "história" e à "cultura", e a preocupação "em não deixar morrer" à "ciência" (Arquidiocese, 1988).

No ano seguinte, a Arquidiocese produziu também um pequeno texto chamado de Crenças e Pensares do Povo Tapeba (Id., 1989). O texto 
apresentava frases de indivíduos com idade maior que 50 anos e foi elaborado a partir da transcrição de entrevistas que abordavam concepções de "Deus", "alma", "demônio", "morte" e "superstições". O documento, nos parágrafos iniciais, retomou o tema da morte de Perna-dePau e deixava transparecer a imagem de uma população sem liderança (sem cacique) - e sem pajé -, concebendo mais uma vez um estado de desorganização social, talvez, sugere o texto, por ser "dispersa" espacialmente e "outros fatores mais".

As representações elaboradas pela Arquidiocese e outros agentes definiam os tapebas como índios sofridos, miseráveis, em estado de desorganização social e cultural, aculturados e sem memória coletiva, miscigenados culturalmente e racialmente. Um conjunto de temas foi objeto de polêmicas que colocavam em oposição sistemática enunciados que diziam que os tapebas não eram índios porque moravam em "favelas" ou no meio urbano e que conheciam e falavam a língua portuguesa, não possuíam uma "tradição", nem "língua indígena", desconhecendo a "cultura e tradição indígena". Por outro lado, a Arquidiocese e outros agentes, apesar de operarem com representações semelhantes, procurou intervir na situação fazendo o trabalho do "resgate" e produzindo uma "cultura", "história" e "geografia" para os tapebas. Os índios, segundo a Igreja, apesar das semelhanças com a população regional, apesar do processo de aculturação, não estavam integrados ou tinham deixado de ser índios, mas para que isso voltasse à tona era preciso "resgatar" a "verdadeira história e memória". Era preciso, como diziam os textos, revitalizar o que "restou" ou "sobrou" da "cultura"; apesar de aculturados, este processo não teria sido completado plenamente. $O$ trabalho do resgate tentou então recuperar os saberes tradicionais, procurou também vincular os índios à atividades econômicas tidas como tradicionais, conectando-se a ambientes geográficos não-urbanos, a objetos materiais que indicavam a sobrevivência de uma "cultura" indígena. Em seguida, mostro de que modo alguns destes saberes foram apropriados pelos professores indígenas.

\section{A "cultura" na política local e a politização da cultura no movimen- to de professores indígenas}

Em espaços de ação distintos e envolvendo outros atores, a segunda situação que interessa aqui está conectada com o período anteriormente descrito na medida em que as representações produzidas sobre os tapebas foram apropriadas pelos professores, demonstrando relativo grau de 
amadurecimento e protagonismo do movimento indígena. No entanto, os professores não somente respondem aos discursos da Arquidiocese, pois com a produção do livro didático Memória Viva dos índios Tapeba: terra demarcada, vida garantida... e a criação de inúmeros eventos que celebram a "cultura tapeba" - situações que analisarei mais à frente, eles simultaneamente inserem-se no idioma contemporâneo das políticas de reconhecimento identitário, buscam desenhar autoetnografias, e respondem, sobretudo, a um contexto atual ainda marcadamente racista que insiste em posicionar negativamente ou duvidar da existência de índios em Caucaia.

É possível perceber uma mudança sensível dos discursos e ampliação dos elementos táticos usados pelo movimento indígena com a entrada em cena dos professores, como por exemplo, o emprego de um vocabulário específico em sintonia com a linguagem utilizada nos documentos oficiais e a produção de um calendário de atividades relacionadas com as escolas indígenas, tais como festas, feiras, celebrações e inúmeros outros eventos. Numa escala mais ampla, tais mudanças estão relacionadas com reconhecimento legal do pluralismo cultural por parte dos estados-nações latino-americanos, transformações ocasionadas principalmente pelas intervenções de organismos internacionais de financiamento, nos interesses externos na governabilidade dos regimes políticos no continente e em modelos de desenvolvimento pautados na idéia de capital humano e na reforma do Estado, sugerindo a emergência de um multiculturalismo neoliberal (Assies, 2002; Hale, 2002; Gustafson, 2002). Estes elementos geram uma gramática hegemônica para o mundo contemporâneo da política com a proeminência da politização generalizada da cultura na ordem emergente, em especial na lutas por reconhecimento (Fraser, 2003).

No Brasil não poderia ser diferente. Desde o início da década de 90, iniciou-se um processo de descentralização administrativa das políticas direcionadas aos povos indígenas, em especial da saúde, educação, desenvolvimento rural e meio-ambiente. De 1995 em diante, estas ações "[...] adquiriam contornos próximos à organicidade de políticas" (Souza Lima et al, 2004). E, na educação indígena, foram constituídos os marcos jurídicos, estabelecidos os princípios de interculturalidade, bilinguismo, especificidade e diferença como "características" ou "fundamentos" das políticas ${ }^{18}$ e, ainda em 1995, era o primeiro ano em que as secretarias estaduais de educação poderiam solicitar recursos para o financiamento de projetos na área (Grupionni, 1997) ${ }^{19}$.

Porém, deve-se levar em conta que, assim como em outros países, tais reformas foram regionalmente fragmentadas em sua implementa- 
ção, significados e efeitos (Gustafson, 2002; Souza Lima et al, 2004). No Ceará, as reformas na esfera da educação indígena foram inicialmente diretamente influenciadas pelos organismos internacionais, uma vez que as autoridades estaduais tinham um bom trânsito nas agências multilaterais de financiamento (Zibas, 2005), fazendo com que o fenômeno da globalização das agendas educacionais alcançasse o Estado um pouco mais cedo, se comparado às outras unidades da federação, no Nordeste.

Os documentos oficiais que estabeleceram os primeiros rumos das políticas para a educação escolar indígena apareceram no Ceará por volta da segunda metade da década de 90, especificamente em 1996, quando tem início a produção de um discurso em sintonia com as diretrizes políticas nacionais e o processo de implementação de políticas específicas: educação infantil, educação especial e educação indígena. Porém, somente no ano de 1998 foi colocada em prática, pela Secretaria de Educação Básica (SEDUC), o Programa de Expansão da Escola Indígena no Ceará, estabelecendo cinco metas para a educação escolar indígena: elaboração do censo escolar, formação de professores, ampliação e construção de prédios escolares, elaboração de material didático específico e a realização de eventos. A entrada em cena do órgão oficial significou a definição de uma agenda de ação política, a disponibilidade de recursos humanos e materiais, a realização de censos estatísticos, o estabelecimento de metas a serem cumpridas, a adoção de um vocabulário específico e, sobretudo, uma política de reconhecimento dos agentes da educação indígena, em especial do professor indígena.

Este vocabulário específico fazia referência a temas, imagens e categorias usadas pelos agentes e pretendiam "reafirmar", "afirmar", "buscar" ou "valorizar" a "identidade" e a "cultura" dos tapebas (Aires, 2005) e apontavam para a adoção de um padrão discursivo comum nas propostas destinadas à escolarização indígena que daria uma homogeneidade ao campo discursivo que toma como objeto a educação escolar indígena instaurada no Brasil recentemente por diversos agentes, que:

[...] teriam convergido, nos últimos anos, em salientar em seus discursos, seja como parte de uma militância política, seja apenas em termos retóricos, a defesa da diversidade e da pluralidade cultural, o direito ao exercício da diferença e da autodeterminação das sociedades indígenas. Neste quadro, a educação formal reclama para si o sentido de "arma" e "ferramenta", ou seja, instrumento tanto para o fortalecimento e a manutenção da identidade étnica, como também meio para a aquisição de outros fins, em particular, um maior domínio das relações com a sociedade nacional. (Paladino, 2001, p. 99). 
Estes discursos, de acordo com a autora supracitada, supervalorizam a escola ("narrativas sobre o poder transformador da escola") como meio de conscientização para o contexto das relações interétnicas e a revitalização cultural.

Com estas transformações nos planos internacional, nacional e local, pode-se, de modo resumido, enumerar os efeitos destas mudanças para os tapebas, em especial com o foco no professor indígena: os professores alcançam prestígio socioeconômico e político nas localidades indígenas, alterando inclusive a configuração de mecanismos de poder dos grupos; criam sua própria organização, a Associação dos Professores Indígena Tapeba (APROINT); ocupam postos importantes em outras organizações indígenas, como por exemplo, a Associação das Comunidades dos Índios Tapeba (ACITA). Ocorre também uma ampliação significativa da participação dos professores em instâncias importantes de discussão sobre assuntos relacionados à educação indígena nos níveis local, nacional e, em menor medida, internacional. E, principalmente, os professores posicionam-se como intelectuais de base, fornecendo um conjunto de respostas para as situações que de modo recorrente localizam os índios tapebas como aculturados.

Com esse cenário genericamente delineado, focalizo agora o ano de 1999, especificamente a ocasião em que teve início a pesquisa para a confecção do livro didático Memória Viva... Trato a produção do livro como situada em zonas de contato (Pratt, 1991; Rappaport, 2003, p. 573), ou seja, em "[...] espaços sociais onde as culturas se encontram, se chocam, e se negociam, em contexto de relações de poder assimétricas.". Nestes espaços são geradas as autoetnografias que, de acordo com Pratt, são uma interpretação cultural híbrida construída em resposta ou em diálogo com os textos coloniais, não são exatamente formas de expressões autóctones ou auto-representações, mas envolvem uma apropriação e seleção dos idiomas do colonizador.

Portanto, como um discurso pluralista e complexo, o livro Memória Viva... e outras produções culturais dos tapebas podem ser vistas como autoetnografias que endereçam seus discursos para um número variado de agentes localizados em múltiplos espaços.

Como resultado das ações da SEDUC em apoiar a produção de material didático para as escolas indígenas, a feitura do livro Memória Viva.... elegeu o professor como agente principal da empreitada. A escolha dos temas, a mobilização dos envolvidos para a escrita dos textos e desenhos, além da realização das atividades de pesquisa, foram definidas pelos professores. O princípio metodológico do trabalho foi fornecido 
por um pressuposto que vem sendo formulado há mais de uma década pelos documentos oficiais que tratam da educação escolar indígena e que apontam para a importância da pesquisa na formação dos professores indígenas e elaboração dos currículos diferenciados (Brasil, 1998; 2002). A escolha desse princípio decorreu principalmente dos agenciamentos realizados nos cursos de formação de professores, em que os especialistas assinalavam a importância da pesquisa da "cultura" para produzir conhecimentos adequados ao modelo de educação intercultural. Em Caucaia, no entanto, os tapebas realizaram a pesquisa sem a supervisão dos especialistas e anunciavam isso com orgulho, "o livro foi feito por nós mesmos".

Os temas das pesquisas foram organizados assim: o primeiro agrupamento de textos focalizaram "a história dos tapeba" e outras "histórias" (do pescador Sr. Manuel, ou as "lendas da nossa lagoa"). Os escritos consistem basicamente em pesquisas dos professores entrevistando o pajé, o cacique ou pessoas idosas, e procuram em geral abordar o tema do "cacique" Perna-de-Pau, a "origem" dos tapebas, a presença indígena no Ceará e a "invasão" das terras indígenas. O segundo grupo focaliza o toré e, finalmente, um grupo de textos sobre a escola "diferenciada".

Exploro adiante os textos que discorrem sobre a "história dos tapeba", a "origem" e sobre o toré. Desse conjunto, alguns temas que se encontram em documentos elaborados pela Arquidiocese foram continuamente tratados. Um dos temas foi a morte de Perna-de-Pau como um fator responsável pela "desagregação do grupo". A exposição nos remete a domínios temporais cronologicamente datados - tempo em que Perna-de-Pau era vivo, em que ele "impunha respeito e sentido na união da comunidade", antes de 1955 -, e o momento, após a morte de Perna-de-Pau, de 1955 em diante, ocasião em que acontece a "desagregação do grupo".

Logo em seguida, por volta da década de 1980, o tempo em que os tapebas "estavam organizados em uma associação", talvez poderíamos dizer o tempo da agregação do grupo. Determinado trecho remete também os tapebas a um tempo que cronologicamente não pode se definido, mas é um tempo em que os índios pescavam e comercializavam mudas de palmeiras ornamentais, das "atividades econômicas tradicionais dos índios". Em seguida, a autora expõe as atividades econômicas diversificadas e sazonais dos tapebas para finalizar com a exposição sobre o "trabalho de palha" que era importante para a confecção das "vestes usadas nos rituais sagrados". O mesmo tema da "desagregação" foi desenvolvido em outro texto apresentado no livro com a mesma estratégia 
narrativa, contrastando o tempo do "cacique" Perna-de-Pau, em que a "[...] a tribo morava em ocas, feitas de barro e palha, portas feitas de talos, no acostamento do trilho em Capuan" e um tempo em que "[...] alguns se destacaram e foram morar em lugares situados em Caucaia.".

É possível observar nos textos uma exposição cronológica que opõe três períodos: (1) aquele em que a presença de Perna-de-Pau impunha respeito e união ao grupo, tempo em que viviam em "ocas" que mais parecem casas de taipas "feitas de barro e palha, portas feitas de talo"; (2) quando da morte de Perna-de-Pau como fator responsável pela desagregação do grupo; (3) no período atual, em que os tapebas se organizam numa associação e se "destacaram", melhorando a condição socioeconômica, e foram morar em Caucaia. Sobre o aspecto "cultural", os textos no período da Arquidiocese dão ênfase aos efeitos negativos da desagregação. Por outro lado, no livro Memória Viva..., os textos usam sempre um artifício narrativo em que, antes da morte de Perna-de-Pau, ele deixou "todas as culturas e costumes". Para os professores indígenas, "cultura" era sinônimo de "herança" deixada por Perna-de-Pau; era sinônimo também de "atividades econômicas", "remédios caseiros", estando relacionada ao artesanato, ao trabalho com barro - apesar das mudanças culturais ocasionadas "pelas inovações do branco" -, e ao toré.

Um trecho especial do livro foi dedicado à dança do toré. Aqui se encontram transcrições das letras das músicas, desenhos de crianças que representam círculos de índios dançando com as maracas na mão. $\mathrm{O}$ toré foi apresentado como um "ritual sagrado", "uma dança sagrada", que era "dançado em agradecimento ao deus Tupã, pelas nossas conquistas e retomadas", trazendo uma "sensação de paz, tranqüilidade além de espantar os males" (Tapebas, 2000, p. 27). A maraca, instrumento musical de percussão, também era objeto de comentários e de uma apresentação visual que explorava um domínio da cultura material; foi apresentada como um "escudo cultural" e sua confecção apareceu recheada com um vocabulário específico: o fabrico do instrumento musical, afirmou o texto, foi um "ritual cultural e religioso". A ser confeccionada, passava por um "ritual de enfeite, adornos para, por último, ser consagrada, porque ela irá junto com nós exaltar, engrandecer nossos deuses que são dignos de receber o que há de melhor em nossas terras". E finalizou o professor: "É mais uma arma no combate aos posseiros." (Ibid., p. 32).

As formulações dos professores podem ser vistas como uma autoetnografia na medida em que emergem em resposta ou diálogo com textos ou discursos oriundos de outros agentes, situados em tempos e 
espaços distintos. Tal como num processo de articulação e posicionamento (Li, 2000) envolvem seleção e apropriação de um complexo sistema de símbolos que são definidos e re-definidos em meio à interação com inúmeros agentes que envolvem ao mesmo tempo pocisionamentos essencialistas, mas também formulações sobre a cultura que estão bem mais próximos dos estudos culturais do que das definições clássicas da Antropologia ${ }^{20}$ (Rappaport, 2003), como por exemplo, quando os textos tratam a cultura como "arma", "escudo", elemento fundamental nas lutas políticas, não postulando portanto, simplesmente uma essência, mas um posicionamento que permite a mobilização coletiva.

Não somente o livro Memória Viva..., mas também a Festa da Carnaúba e a Feira Cultural foram eventos criados pelos professores em que apresentavam uma versão da "cultura" tapeba para o público nãoindígena e, nestas ocasiões, chamavam a atenção das autoridades e dos meios de comunicação de massa, em especial as TVs e jornais locais, para os problemas das escolas, utilizando para isso a retórica culturalista.

Certa vez foi divulgada num jornal a suposta declaração de um professor tapeba: "Nós queremos mostrar à sociedade cearense o nosso modo de vida e que ainda utilizamos a medicina tradicional", e ainda: "Com a divulgação da festa, mostramos para o Brasil que no Nordeste, no Ceará, estamos vivos e fortes." (Agência, 2002). Eram também exploradas pelos professores as iniciativas empregadas em "resgatar" a "cultura". Um professor prestou a seguinte declaração a um jornal: "Os professores passam esses ensinamentos aos alunos, que não sabiam fazer as peças antes"; "A festa, que acontece há três anos, é uma herança dos antepassados. Por algum tempo, a tradição do dia 20 de outubro caiu no esquecimento. "Com o surgimento das escolas indígenas, foi revitalizada" (Ibid.). As práticas e imagens eram direcionadas para inúmeros agentes, um exemplo disso foi a inserção dos esportes indígenas (arremesso de lança, queda de braço, arco e flecha, cabo de força, natação, triathlon, corrida com a tora da carnaúba, briga de galo) durante o evento da Feira Cultural, na consciência discursiva de determinados professores indígenas a criação dos jogos indígenas tapebas aconteceu em resposta a um outro evento realizado no Ceará, os Jogos Indígenas Nacionais, que contou com a participação de líderes expressivos do movimento indígena no Brasil. O evento negou a participação dos povos indígenas locais, usando um argumento bastante conhecido: os povos indígenas no Ceará não possuem "esportes tradicionais", tal como em outros povos presumidos como mais autênticos. Portanto, nesse caso, os esportes indígenas na Feira Cultural ofereciam uma resposta ao movimento indígena nacional e seus ideais de autenticidade. 
Durante a realização da feira havia uma preocupação em definir o que é cultura. Os professores debatiam entre si qual o sentido da palavra cultura e, vez por outra, significados entravam em disputa, os quais giravam em torno dos autentificadores indígenas, ou seja, dos critérios legítimos que estavam em jogo na definição do que é ser autenticamente indígena. Os argumentos opunham basicamente duas posições.

A primeira defendia um domínio maior sobre o que deveria ser apresentado como traços autenticamente representativos da "cultura tapeba" - opinião defendida por professores e lideranças, grupo de indivíduos eleitos para dialogar com a mídia, pesquisadores, ONGs, entre outras esferas da sociedade. Era a favor de um controle do artesanato confeccionado com palha ou outros materiais tidos como de origem indígena, a exibição da dança do toré, produtos da medicina tapeba e outros. Em geral, os discursos faziam oposição para as contradições em torno da prática de determinadas professoras que levavam produtos feitos com crochê, ou que usavam salto alto e óculos escuros e, ao mesmo tempo, cobriam seus rostos com pinturas nos dias da feira e festa. Crochê, salto alto, óculos escuros, calça jeans e plásticos eram elementos percebidos como contraditórios em relação à "cultura indígena", como um professor falou: "[...] daqui a pouco as pessoas vão trazer calça jeans e vender como coisa tapeba."

A outra posição, menos explícita nos discursos públicos, mas presente em vários momentos da feira, defendia posições que distanciavamse dos discursos de líderes do movimento indígena e que eram a favor de idéias amplas relacionadas ao "progresso", "evolução do índio" e temas sobre o racismo.

Se os discursos da "cultura" eram, no entanto, uma espécie de face pública dos tapebas, um estilo discursivo situacional (Foley, 1996), explorado inicialmente pelos líderes, posteriormente incrementado pelos professores e que serviram de base para um discurso mobilizador e politizado; por outro lado, em geral em esferas privadas, ou nos conflitos envolvendo professores e comunidade, os ideais de um modelo de educação intercultural ou de escola diferenciada eram postos em dúvida pelos próprios tapebas e, neste aspecto, algumas noções "consensuais" sobre esta face pública dos tapebas eram também colocadas em descrédito (como mencionei anteriormente), gerando não somente ação, mas reflexão sobre o ideal implementado.

Os projetos de formação de professores que enfatizavam a pesquisa dos "etnoconhecimentos" com a retórica de valorização da cultura e 
tantas outras coisas, também eram alvo de questionamento por parte dos professores, tal como neste diálogo, em que a SEDUC realizou uma dinâmica de grupo na qual os tapebas deveriam discutir e posteriormente apresentar a "escola que queremos":

Ana: Se é uma escola diferenciada quer dizer que a gente vai estudar só... Assim, eu penso assim, essa formação, se é uma escola diferenciada e como é que vai ser essa formação, é só sobre coisa indígena [...] os menino a gente não vai ensinar só coisa indígena, tem que ensinar coisa de fora também.

Sebastiana: De fora também.

José: Preparar para...

Ana: Para o amanhã...

José: Para o amanhã porque a modernidade tá aí...

Ana: Vai que ele vai pra faculdade...

José: Ele não pode ficar só preso também.

Ana: Ele vai pra faculdade sem que nunca ter feito a realidade lá fora...

Nilda: De segunda até quinta é dou aula normal, agora que é sextafeira que é aula cultural.

Sebastiana: Todo mundo é assim.

José: Aquela menina colocou assim, o seguinte. Tanto deveria aprender as coisas indígenas, quanto as coisas novas para o futuro, eu não sei quem colocou depois assim que o professor indígena mais ou menos como se defender dos brancos, lá fora...

Nesta conversa, a preocupação dos professores fazia justamente referência aos excessos em torno das ações dos agentes preocupados em "valorizar", "respeitar", "resgatar" a cultura. No caso, a preocupação deles era exatamente oposta, era com a "modernidade", com o "amanhã", com o ensino das "coisa[s] de fora" e o acesso ao ensino superior. Em certa ocasião, um professor tapeba me disse que os líderes indígenas "em todos esses anos de luta" vêm ensinando em suas famílias "o que é ser um índio", mas um "índio moderno". De acordo com Turner (1993), para os caiapós o valor de uso de mercadorias "civilizadas" - roupas, rádios, gravadores, aviões, etc. - os distancia de estereótipos ligados à 
"selvageria"; para os tapebas parece ocorrer justamente o oposto, eles usam e desejam alguns destes objetos e, ao mesmo tempo, manipulam a imagem de "índios" como sujeitos que caçam, pescam, vivem em ocas, entre outros costumes, ou mesmo a idéia de "índio moderno" ou, como diz o professor a seguir, que "devem a acompanhar a evolução":

Você vê que as crianças cantam músicas evangélicas, cantam... Já vai saindo um pouco da cultura do índio. A gente luta realmente por uma coisa daquilo que nós praticávamos antigamente. Mas eu creio que o resgate, não esteja ele todo voltado só pra aquelas coisas, pelo menos a metade, como fazer colares, a dança do toré, fazer as roupas e essas coisas. O mundo ele tá evoluindo, as pessoas devem, na minha opinião, devem acompanhar a evolução.

O paradigma da pesquisa presente nos projetos de formação de professores também era questionado. Numa ocasião, uma professora pôs em dúvida a disposição e os próprios saberes requeridos pelo modelo de educação intercultural, afirmando que os "os mais velhos não querem se reunir com os mais novo pra conversar com a gente" ou "eles não passa pra gente", "os mais velhos dizem que não são" índios. De outra feita, uma professora declarou que na localidade onde ela ensinava "as mães nunca foram em reunião, nunca ensinaram o toré". Alguns, nesta ocasião, chegaram a afirmar que o ensino supletivo apresentava "mais vantagem" se comparado à proposta que estava sendo discutida pela Secretaria de Educação.

As preocupações com a equivalência do diploma entre o curso diferenciado e os outros oferecidos para não-indígenas, a todo instante eram aviltadas pelos professores. Esse foi apenas um dos aspectos da questão vinculada especificamente à pratica discursiva deste segmento da população indígena, líderes e professores, pois a educação, ao invés de produzir situações homogeneizadoras - pressuposto explorado demasiadamente numa certa literatura antropológica e educacional - levaria também à heterogeneidade (Rival, 2000) de práticas, algumas vezes contraditórias e conflitantes, criando no interior do grupo indígena disputas em torno do processo de objetificação da tradição e, até mesmo, duvidando em alguns momentos da obrigação dela.

\section{Considerações finais}

Explorei neste artigo as possibilidades de análise que vão além do conceito de "invenção" ${ }^{21}$ ou do uso estratégico do essencialismo. A ação dos professores tapebas demonstra de que modo eles situam-se em relação 
aos discursos, imagens e agendas definidas por um conjunto variado de agentes que, em geral, competem por definição das identidades indígenas e quase sempre reclamam por tradicionalidade, autenticidade ou valorização da "cultura" por parte dos tapebas. Os professores, por outro lado, articulam sua identidade em termos de um conjunto de características que são reconhecidas como indígenas pela mídia, população regional, ONGs e outros envolvidos, pois as lutas por recursos são simultaneamente lutas por significados.

Paralelamente, os professores geram uma infinidade de significados novos sobre "cultura", pois não apelam a um referente étnico primordial, mas constroem suas identidades por meio da organização sistemática de materiais culturais oriundos de diversos contextos, não exatamente fundados em meio ao acesso a memórias orais explícitas destes eventos. A ação dos professores ao qual fiz referência aponta para as possibilidades dadas e criadas pelos docentes indígenas e que têm permitido de modo complexo a articulação das identidades indígenas no cenário contemporâneo.

Retomando os temas postos pela Arquidiocese, procurei mostrar que os enunciados tentavam provar a existência de uma nação ou de um grupo étnico e que estas práticas podem ser localizadas nas transformações da Igreja Católica. Como nos lembra Handler (1987), o tratamento dado ao tema do "resgate" depende da imaginação de uma substância cultural e histórica, de uma realidade natural em que as pessoas de uma determinada coletividade vivem em posse de uma cultura e uma história particular.

Para o caso dos tapebas, e também de outros povos indígenas no Ceará, uma parte importante desta "existência" foi produzida, criada a partir das disputas entre agentes indigenistas e os próprios tapebas. Ramos (1995), numa análise sobre o ativismo indigenista no Brasil, aponta que os índios "[...] 'de carne e osso' começam a ser filtrados, sua alteridade indomada, criadora de desordem em potencial ou de fato para as entidades, sofre um processo de domesticação e surge então um modelo de índio, que seria uma espécie de 'índio-modelo'." (Ramos, 1995, p. 9-10), um "índio hiper-real". É este índio modelo que as representações e ações do indigenismo criam (SAID, 1996), mas criam não apenas um conhecimento sobre os índios, mas também "[...] a própria realidade que parecem descrever." (Said, op. cit., p. 103).

Os professores indígenas, por outro lado, inseriam-se neste cenário adotando o vocabulário culturalista, seja o da Igreja, ou o do multiculturalismo neoliberal, da Secretaria de Educação, mas almejam 
ir além dele, usando imagens, festas, comemorações e textos orais que foram divulgados nas escolas, indígenas e não-indígenas, no contexto local, na mídia e em tantos outros lugares. Tais instituições culturais eram sistematicamente utilizadas para borrar, reproduzir ou ir contra as representações corriqueiras sobre os tapebas, uma maneira que os jovens professores encontravam para obter controle sobre as representações que insistiam em posicionar os tapebas como índios "aculturados", menos autênticos, "misturados", ou declarações de que não eram índios.

\section{Notas:}

${ }^{1}$ Localizada na região do Nordeste brasileiro, Caucaia situa-se contiguamente a Fortaleza, capital do Estado do Ceará, desta distando $11 \mathrm{~km}$ pela rodovia BR 222 (Fortaleza - Teresina). O município situa-se na Região Metropolitana de Fortaleza, da qual fazem parte, além de Fortaleza e Caucaia, os municípios de Aquiraz, Eusébio, Guaiúba, Itaitinga, Maracanaú, Maranguape e Pacatuba. Os tapebas, com uma população em torno de 5 mil indivíduos, estão distribuídos em inúmeros núcleos populacionais no município de Caucaia.

${ }^{2}$ A Equipe de Apoio às Comunidades Rurais, órgão anexo à Arquidiocese de Fortaleza, era encarregada de prestar assessoria às populações camponesas.

${ }^{3}$ Movimento de educação popular que tem sua constituição relacionada à experiência de alfabetização de adultos empreendida pela Arquidiocese de Natal, posteriormente, a de Aracajú. Em 1961, o governo brasileiro aceitou a proposta da Conferência Nacional dos Bispos do Brasil (CNBB) de criação de um amplo movimento de educação da população rural adulta, executado pela CNBB, com apoio técnico e financeiro do governo brasileiro (Nobre, 1990).

${ }^{4}$ Refiro-me às transformações instauradas na Igreja a partir do Concílio Vaticano II (1962-1965) (Montero, 1995; 2006).

${ }^{5}$ Aloísio Lorscheider iniciou sua trajetória eclesial em altos cargos da Igreja já quando eleito bispo, no ano de 1962, ocasião em que atuou como uma das lideranças da Conferência Nacional de Bispos do Brasil (CNBB) no Concílio Vaticano II e, logo em seguida, passou a exercer cargos na CNBB, inclusive ocupando o de presidente da conferência por dois mandatos seguidos, entre 1971 e 1978, durante a ditadura militar. No mesmo período foi também eleito presidente da Conferência Episcopal Latino Americana (CELAM).

${ }^{6}$ Arruti (2006) levanta a hipótese de uma formação discursiva, de longa duração e relativamente autônoma, que recentemente, por intermédio da "pedagogia popular", possibilitou uma prática não missionária articulada em torno de uma linguagem cultural. O MEB, segundo o autor, teria sido responsável, no sertão sergipano, pela retomada dessa linguagem pelos missionários. No Ceará, especificamente no caso dos tapebas, as práticas discursivas culturalistas foram retomadas por leigos.

${ }^{7}$ A equipe era constituída por quatro técnicos, porém, somente um deles, o mais próximo a Dom Aloísio, empenhou-se no trabalho inicial com os índios. 
${ }^{8}$ No Ceará, a idéia do "desaparecimento" dos índios foi produzida discursivamente por meio das declarações de políticos e na produção intelectual local, desde a segunda metade do século XIX. E até meados da década de 1980, a Fundação Nacional do Índio (FUNAI) não tinha conhecimento da existência de índios no Estado.

${ }^{9}$ Se no início da ação havia somente um membro diretamente engajado, por volta do final da década de 1980, quase toda a Equipe desligou-se da Arquidiocese, permanecendo somente uma única integrante do corpo técnico original, que passou a constituir o corpo técnico da Pastoral Indigenista.

${ }^{10}$ Utilizo Indigenismo no sentido amplo do termo: “[...] como um complexo edifício ideológico construído sobre diferenças étnicas, uma obra que nunca se completa. É uma Babel de conjunções e disjunções erigida com uma grande variedade de ingredientes que vão desde políticas oficiais, posturas religiosas e laicas sobre o destino dos povos indígenas, de construções antropológicas ou imagens jornalísticas a manifestações dos próprios índios perante a sociedade dominante. A minha definição de Indigenismo não se restringe, portanto, ao indigenismo oficial." (Ramos, 1998, p. 8-9).

${ }^{11}$ Não disponho de uma versão do trabalho em que apareça a paginação do texto original. Por essa razão, no decorrer do texto não indicarei o número da página consultada neste documento.

${ }^{12}$ Os títulos dos documentos são um exemplo dessa estratégia, tal como à carta dirigida à população local intitulada: Povo de Caucaia. Existe Índios no Ceará. Os Tapebas ainda resistem, de 11 de julho de 1986. No decorrer do texto apresento exemplos que procuram comprovar a minha afirmação, no entanto, por ora cito um relatório da Arquidiocese e um de seus esforços: “A segunda vertente do trabalho compreende toda uma série de contatos com a população envolvente dos municípios de Caucaia e Fortaleza, no sentido de demonstrar o direito dos índios Tapeba a terem suas terras devolvidas e demarcadas pelo Poder Público, bem como de afastar e destruir os argumentos apresentados de que aquela população não é indígena..." (ARQUIDIOCESE, s/d).

${ }^{13}$ A noção de orientalismo é empregada neste artigo com a intenção de enfatizar o papel da Igreja na produção de saberes que "orientalizaram" os tapebas. Sobre o uso do termo em contextos etnográficos distintos, mas de modo semelhante, consultar Jackson (1995b), Ramos (1997) e Frank (2002).

${ }^{14}$ Categoria empregada pela Fundação Nacional do Índio nos processos de regularização fundiária.

${ }^{15}$ Documentos de autoria de Jussara Vieira Gomes: Breve informação sobre os índios do município de Caucaia, Estado do Ceará e Relatório sobre os índios do município de Caucaia, Estado do Ceará.

${ }^{16}$ Relatório de Viagem ao município de Caucaia-CE (Rola, 1986).

${ }^{17}$ Conforme Barreto Filho (1994, p. 22), a autora do argumento original parece ser a Deputada Estadual Maria Lúcia Correa que deu a seguinte declaração ao jornal O Povo (1987, p. 4): “Nunca existiu índios Tapebas. O que existe é um grupo de descendentes de um caboclo conhecido pela alcunha de'Perna-de-Pau' que habitou na área de Caucaia no início do século e que teria vivido maritalmente com duas irmãs, 
o que gerou um grupo racial fechado que foi habitar nas proximidades da Lagoa do Babaçu, na estrada da localidade de Garrote, a oeste da sede da antiga Soure, hoje Caucaia."

18 "Características" e "fundamentos" são termos usados no Referencial Curricular para as Escolas Indígenas.

${ }^{19}$ Como o próprio MEC (2002) reconhece, é somente a partir de 1995 (e entre esse ano e o de 2002) que o trabalho do Ministério "toma vulto" e onde são implementadas "as principais linhas de trabalho". No entanto, somente a partir de 1996 e 1997 que o MEC "apoiou" projetos em educação escolar indígena. Conferir, por exemplo, o "Anexo: Relação de projetos apoiado pela CGAEI"). Nessa relação não consta nenhum projeto beneficiado no estado do Ceará (BRASIL, 2002, p. 235-283).

${ }^{20} \mathrm{~A}$ "cultura" para os professores longe de fazer referência a uma totalidade abstrata ou a um passado romantizado, em algumas situações, aparece como a linguagem empregada para a intervenção política. Nessa direção não há utilidade nas distinções clássicas entre genuína/espúria.

${ }^{21}$ A idéia de invenção, além de seus embaraços políticos (Briggs, 1996; Friedman, 1992), deixa de ter rendimento analítico, pois se toda a cultura é produto de uma "invenção" por que então continuamos afirmando, como eu mesmo fiz em outros textos, que os tapebas "inventam" uma cultura?!

\section{Referências}

AGÊNCIA de Informação Frei Tito para a América Latina. In: COSTA, Dioneide. Tapeba reverenciam a natureza e reafirmam tradição local na Festa da Carnaúba. Disponível em: <http://www.adital.org.br>. Acesso em: 22 out. 2002.

AIRES, Max Maranhão Piorsky. Visibilidade, estratégias políticas e colonialismo: as demandas por uma escola para os índios Tapeba. Notícias de antropologia y arqueologia, Argentina, v. 2, 2003. (Edição especial: Educación y Antropología II).

Aprendendo a ser "índio" tapeba. SEMINÁRIO CULTURA RELAÇÕES DE GÊNERO E MEMÓRIA, 3., 2005, Paraná. Anais... Paraná: [s.n.], 2005.

ANTEQUERA, Nelson. Educación y pueblos indígenas: una reflexión desde Bolívia. Dialogo Antropológico, Cd. México, n. 3, p. 15-21, abr./jun. 2003.

ARQUIDIOCESE de Fortaleza. Equipe de Apoio às Comunidades Rurais. Cadastramento dos Índios Tapeba. Fortaleza, out. 1986.

. Pastoral Indigenista: a medicina dos tapebas. Fortaleza: [s.n.], 1988.

. Equipe Arquidiocesana de apoio à questão indígena. Crenças e pensares do povo Tapeba. Caucaia, ago. 1989.

. Pastoral Indigenista. Caminhada da Pastoral Indigenista da Arquidiocese de Fortaleza de 1985 a 1991: com os índios e não-índios dos municípios de Caucaia (índios Tapeba) e (Aquiraz - Genipapo-Kanindé). Resumido. Fortaleza, jul. 1991a. . Pastoral Indigenista. Relatório de atividades no ano de 1991. Fortaleza, dez. 1991b. 
ARRUTI, José Maurício. A produção da alteridade: o toré e as conversões missionárias e indígenas. In: MONTERO, Paula (Org.). Deus na aldeia: missionários, índios e mediação cultural. São Paulo: Globo, 2006.

ASSIES, Willem et al. Los pueblos indígenas y la reforma del Estado en América Latina. Papeles de Población, Toluca, n. 31, p. 95-115, jan./mar. 2002.

ASSOCIAÇÃO das comunidades do rio Ceará. Estatuto da Associação das Comunidades do rio Ceará. Caucaia, ago. 1985.

AVALIAÇÃO das comunidades do rio Ceará realizada aos 04/04/92 no convento das irmãs Cordimarianas em Caucaia-CE. Fortaleza, fev. 1992.

BAINES, Stephen G. Imagens de liderança indígena e o Programa Waimiri-Atroari: índios e usinas hidrelétricas na Amazônia. Rev. Antropol., São Paulo, v. 43, n. 2, p. 141-163, 2000.

BARRETO FILHO, Henyo T. Tapebas, tapebanos e pernas-de-pau: etnogênese como processo social e luta simbólica. Dissertação (Mestrado em Antropologia Social) PPGAS/MN/UFRJ, Rio de Janeiro, 1992.

. Tapebas, tepebanos e pernas-de-pau de Caucaia, Ceará: da etnogénesis como processo social e luta simbólica. Série Antropologia, 165. Brasília: DAN/UNB, 1994. BRASIL. Ministério da Educação e do Desporto. Referencial curricular nacional para as escolas indígenas. Brasília, 1998.

. Referencial para a formação de professores indígenas. Brasília, 2002.

BRIGGS, Charles. The Politics of Discursive Authority in Research on the "Invention of Tradition". Cultural Anthropology, v. 4, n. 11, p. 435-69, 1996.

BRIONES, Claudia. Viviendo a la sombra de naciones sin sombra: poéticas y políticas de (auto) marcación de "lo indígena" en las disputas contemporáneas por el derecho a una educación intercultural. In: FULLER, Norma. Interculturalidad y Política: desafíos y posibilidades. Lima: Red para el Desarrollo de las Ciencias Sociales en el Perú, 2002.

CAVALCANTI, Ricardo Antonio S. Presente de branco, presente de grego?: escola e escrita em comunidades indígenas do Brasil Central.Dissertação (Mestrado em Antropologia Social) - PPGAS/MN/UFRJ, Rio de Janeiro, 1999.

CEARÁ. Secretaria da Educação Básica (SEDUC). Todos pela educação de qualidade para todos: a caminhada cearense. Fortaleza: SEDUC, [s.d.].

. Coordenação de Planejamento e Política Educacional: mapeamento dos municípios das escolas indígenas no Ceará. 1998.

. II Seminário de Educação Escolar Indígena no Ceará. Fortaleza, 1998. [Folder]

. Projeto de Curso de Formação para o Magistério Indígena. Fortaleza, jun. 2001.

[Versão Preliminar]

Despacho. Processo n. 01192346-6. Fortaleza, 17 jun. 2001.

COELHO, Esmerino O. A. Memorial apresentado por Esmerino Arruda para a reunião promovida pelo governo do Estado do Ceará sobre a Portaria n. 2384/87 da FUNAI. Caucaia, mai. 1988. 
COLLET, Célia. Quero Progresso Sendo índio: o princípio da interculturalidade na educação escolar indígena. Dissertação (Mestrado em Antropologia) - PPGAS/ MN/UFRJ, Rio de Janeiro, 2001.

DAMASCENO, Maria N. Pedagogia do engajamento: trabalho, prática educativa e consciência do campesinato. Fortaleza: EUFC, 1990.

DEAN, Bartholomew. State Power and Indigenous Peoples in Peruvian Amazonia: a Lost Decade, 1990-2000. In: MAYBURY-LEWIS, David (Org.). The Politics of Ethnicity: indigenous peoples in Latin American States. Cambridge: Harvard University Press, 2002.

ESCOBAR, Arturo. El "postdesarrollo" como concepto y práctica social. In: MATO, Daniel (Coord.). Políticas de economía, ambiente y sociedad en tiempos de globalización. Caracas: Facultad de Ciencias Económicas y Sociales, Universidad Central de Venezuela, 2005.

1997.

Antropología y desarrollo. Revista Internacional de Ciencias Sociales, n. 154,

FOLEY, Douglas. The Silent Indian as a Cultural Production. In: LEVINSON, Bradley; FOLEY, Douglas; HOLLAND, Dorothy C. (Eds.). The cultural production of the educated person: critical ethnographies of schooling and local practice. New York: State University of New York, 1996.

FRANK, Erwin H. A construção do espaço étnico roraimense, ou: os Taurepáng existem mesmo? Rev. Antropol., São Paulo, v. 45, n. 2, p. 287-310, 2002.

FRASER, Nancy. A justiça social na globalização: redistribuição, reconhecimento e participação. Revista Crítica de Ciências Sociais 63, Coimbra, p. 7-20, out. 2002.

FRIEDMAN, Jonathan. The Past in the Future: History and the Politics of Identity. American Anthropologist, v. 94, n. 4, p. 837-859, 1992.

GALLOIS, Dominique. De Arredio a isolado: perspectivas de autonomia para os povos indígenas recém-contactados. In: GRUPIONNI, Luís. D. B. (Org.). Índios no Brasil. São Paulo: Secretaria Municipal de Cultura, 1992.

GARCIA, Maria Elena. Making Indigenous Citizens: identities, education, and multicultural development in Peru. Stanford: Stanford University Press, 2004.

GRUPIONI, Luís Donisete Benzi. Ecola Indígena: caso particular de escola? In: D'ANGELIS, Wilmar; VEIGA, Juracilda (Orgs.). Leitura e escrita em escolas indígenas. Campinas: Mercado de Letras, 1997.

Do Nacional ao local, do federal ao estadual: as leis e a Educação Escolar Indígena. In: MARLAN, Marilda Almeida. Congresso Brasileiro de Qualidade na Educação: formação de professores: educação escolar indígena. Brasília: MEC/ SEF, 2002.

GUPTA, A.; FERGUSON, J. Beyond "culture": space, identity, and the politics of difference. Cultural Anthropology, n. 7, p. 6-23, 1992.

GUSTAFSON, Bret. Paradoxes of Liberal Indigenism: Indigenous Movements, State Process, and Intercultural Reform in Bolivia. In: MAYBURY-LEWIS, David (Ed.) Identities in conflict: indigenous peoples in Latin American States. Cambridge: Harvard University Press, 2002.

110 Max Maranhão Piorsky AIRES. De aculturados a índios com cultura:... 
HALE, Charles R. Does Multiculturalism Menace? Governance, Cultural Rights and the Politics of Identity in Guatemala. Journal of Latin American Studies, n. 34, p. 485-524, 2002.

HANDLER, Richard. On having a culture: Nationalism and Preservation of Québec's Patrimoine. In: STOCKING, George W. (Ed.). Objects and Others: essays on museums and material culture. Wisconsin: The University of Wisconsin Press, 1987.

JACKSON, Jean. Preserving Indian Culture: Shaman schools and Ethno-education inthe Vaupés, Colombia. Cultural Anthropology, v. 10, n. 3, p. 302-329, 1995a.

Culture, genuine and spurious: the politics of Indianness in. the Vaupés, Colombia. American Ethnologist, v. 22, n. 1, p. 3-27, 1995b.

LI, Tania Murray. Articulating Indigenous Identity in Indonesia: Resource Politics and the Tribal Slot. Comparative Studies in Society and History, v. 42, n. 1, p. 149-179, jan. 2000.

LOPES DA SILVA, Aracy. Uma “Antropologia da Educação" no Brasil? Reflexões a partir da escolarização indígena. In: LOPES da SILVA, Aracy Lopes da; FERREIRA, Mariana Kawall Leal (Orgs.). Antropologia, história e educação: a questão indígena e a escola. São Paulo: Global, 2001. p. 157-95.

MONTERO, Paula. O problema da cultura na Igreja Católica contemporânea. Estudos Avançados, São Paulo, v. 9, n. 25, p. 229-248, set./dez. 1995.

Índios e missionários no Brasil: para uma teoria da mediação cultural. In: MONTERO, Paula (Org.). Deus na aldeia: missionários, índios e mediação cultural. São Paulo: Globo, 2006.

O POVO. Tapebas vendem areia para garantirem sobrevivência. Fortaleza, p. 8, 1985.

. Maria Lúcia vê fantasia na origem dos índios Tapeba Contesta demarcação das terras e teme provocação de conflitos. 17 ago. 1987, "Política", p. 4.

PACHECO DE OLIVEIRA, João. Uma Etnologia dos “índios misturados"? Situação colonial, territorialização e fluxos culturais.Mana, Rio de Janeiro, v. 4, n. 1, p. 47-77, abr. 1998.

PALADINO, Mariana. Educação escolar indígena no Brasil contemporâneo: entre a "revitalização cultural" e a "desintegração do modo de ser tradicional". Dissertação (Mestrado em Antropologia Social) - Museu Nacional, Rio de Janeiro, 2002.

PRATT, Mary Louise. Arts of the Contact Zone. In: STYGALL, Gail (Ed.). Academic Discourse: Readings for Argument and Analysis. Fort Worth: Harcourt College Publishers, 2000, p. 573-587.

RAMOS, Alcida R. A O índio hiper-real. Revista Brasileira de Estudos Sociais, Rio de Janeiro, n. 28, p. 5-14, 1995.

. Convivência interétnica no Brasil: os índios e a nação brasileira. Série Antropologia, 221. Brasília: DAN/UNB, 1997.

RAPPAPORT, Joanne. El espacio del diálogo pluralista: historia del Programa de Educación Bilingüe del Consejo Indígena del Cauca. In: MATO, Daniel (Coord.). Políticas de identidades y diferencias sociales en tiempos de globalización. Caracas: FACES/UCV, 2003. p. 257-281. 
RIVAL, Laura. Formal Schooling and the Production of Modern Citizens in the Ecuadorian Amazon. In: LEVINSON, Bradley; FOLEY, Douglas; HOLLAND, Dorothy C. (Eds.). The cultural production of the educated person: critical ethnographies of schooling and local practice. New York: State University of New York, 1996.

. La escolarización formal y la producción de ciudadanos modernos en la Amazonia ecuatoriana. In: GUERRERO, Andres. Etnicidades. FLACSO: Quito, 2000.

ROLA, Elia M. Sobre a situação atual dos Tapeba, Caucaia-CE. Informação Técnica, 37. Brasília: Coordenadoria de Terras Indígenas/SG/MIRAD, 1986.

SAID, Edward. Orientalismo: o Oriente como invenção do Ocidente. São Paulo: Companhia das Letras, 1996.

SOUZA LIMA, Antônio Carlos. Um grande cerco de paz. Poder tutelar, indianidade e formação do Estado no Brasil. Petrópolis: Vozes, 1995.

SOUZA LIMA, Antônio Carlos et al. A administração pública e os povos indígenas. In: FALEIROS, V. de P. et al. A era FHC e o governo Lula: transição? Brasília: Instituto de Estudos Socioeconômicos, 2004.

TAPEBAS. Memória Viva dos índios Tapebas: terra demarcada, vida garantida... Caucaia: SEDUC, 2000.

VALLE, Carlos Guilherme. Experiência e semântica entre os Tremembé do Ceará. In: PACHECO DE OLIVEIRA, João. (Org.). A viagem da volta: etnicidade, política e reelaboração cultural no Nordeste indígena. Rio de Janeiro: ContraCapa, 1999.

WRIGHT, Susan. The politicization of "culture". Anthropology Today, v. 14, n. 1, p. 7-15, fev. 1998.

ZIBAS, Dagmar M. L. A reforma do ensino médio no Ceará e suas contradições. Cadernos de Pesquisa, São Paulo, v. 35, n. 124, p. 201-226, 2005.

Recebido em 20 de julho de 2008.

Aprovado para publicação em 22 de agosto de 2008.

112 Max Maranhão Piorsky AIRES. De aculturados a índios com cultura:... 